\title{
Indocyanine Green Clearance and Estimated Hepatic Blood Flow during Mild to Maximal Exercise in Upright Man*
}

\author{
Loring B. Rowell, John R. Blackmon, and Robert A. Bruce \\ (From the Department of Medicine, Division of Cardiology, University of Washington School \\ of Medicine, Seattle, Wash.)
}

Krogh in 1912 (1) postulated the necessity for a large capacity venous reservoir capable of quickly delivering an autotransfusion of blood into the right heart during exercise, particularly in upright man, where Krogh felt venous return may at times be inadequate. Bock and co-workers (2) in their classical work reasoned that increased blood flow to working muscle, related in part to local vasodilation, must be partially effected by decreased splanchnic blood flow. Since the splanchnic region receives 20 to $25 \%$ of the total left ventricular output but extracts only 10 to $25 \%$ of the available oxygen (3), the splanchnic bed is ideally suited for rapid correction for any residual inbalance between left ventricular output and peripheral distribution of flow.

The experimental evaluation of the influence of exercise on splanchnic blood flow, however, has produced conflicting results. Herrick, Grindlay, Baldes, and Mann (4), and more recently Rushmer, Franklin, Van Citters, and Smith (5) did not find a decrease in splanchnic blood flow in dogs undergoing an intensity of exercise far below their maximal capacities. Also plethysmographic studies in man by Sjöstrand (6) led him to conclude that intrathoracic rather than splanchnic blood depots are functionally important in exercise.

In contrast, a study by Bradley (7) and by Wade and co-workers (8), utilizing the sulfobromophthalein sodium (BSP) extraction method, demonstrated that significant decreases in splanch-

* Submitted for publication January 27, 1964 ; accepted April 23, 1964.

Supported in part by grant-in-aid $\mathrm{HE} 908 \mathrm{C} 12$ from the U. S. Public Health Service National Heart Institute and also a grant from the Washington State Heart Association. Presented in part at the 17 th Annual Meeting of the Western Society for Clinical Research, January 1964, Carmel, Calif. nic blood flow do occur in man during mild supine exertion. Although Lowenthal, Harpuder, and Blatt (9) did not obtain evidence for diminished splanchnic blood flow during exercise with the BSP extraction method, the method as applied by these workers was too insensitive to detect any but very large changes. Further evidence regarding splanchnic blood flow during exercise comes from measurements of hepatic arteriovenous (a-v) oxygen difference in normal subjects (10) and in cardiac patients (11). These studies indicate that considerable decreases in splanchnic blood flow occur during moderately heavy exercise in the supine posture particularly in cardiac patients with a severely impaired cardiac output response to exercise. The purpose of the present study was to explore the applicability of a simple and indirect means of assessing changes in hepatic blood flow with exertion and to assess the extremes of these changes during maximal or near maximal exertion in upright man. Heretofore investigations of splanchnic blood flow in exercising man have been carried out using mild to moderate exercise in recumbency; however, cardiovascular responses during exercise in this posture are fundamentally different from those in upright posture (12). Indocyanine green dye (ICG) was used since it is extracted exclusively by the liver (1315). Changes in hepatic blood flow in response to exercise were estimated from changes over resting values of plasma clearance rate of ICG after a single injection. Evidence regarding the validity of these estimates was obtained by measuring simultaneously ICG clearance rate and hepatic extraction efficiency for ICG during rest and upright exercise.

\section{Methods}

The plasma clearance rate of ICG was studied in 10 normal men 19 to 37 years of age with a mean age of 
26 years. Both hepatic extraction and plasma clearance of ICG were determined in five additional normal subjects (17 to 25 years old) and in two cardiac patients, 17 and 25 years old. The two patients were class I, asymptomatic cardiacs who had marked aortic regurgitation. Each exhibited a normal response to the exercise capacity test of Bruce, Blackmon, Jones, and Strait (16). Hepatic circulation was considered to be normal from clinical criteria [an assumption borne out later by normal resting estimated hepatic blood flow (EHBF) and extraction of ICG]. Two additional subjects were deleted from this study because of problems with hepatic venous sampling.

The subjects exercised on a motor-driven treadmill in an air conditioned room maintained at $78^{\circ} \pm 2^{\circ} \mathrm{F}$ and a relative humidity of 55 to $65 \%$. Several days before an experiment the subjects worked at each intensity (and duration) to be employed in the study. Oxygen intake and heart rate were determined at this time, thus familiarizing the subject with these details of the procedure. The maximal oxygen intake was determined by the procedure of Taylor, Buskirk, and Henschel (17).

Plasma disappearance of ICG. All experiments were carried out in the morning with the subjects allowed only fruit juice and black coffee at breakfast. Two $50-\mathrm{cm}$, Lehman no. 5, thin-walled catheters were introduced percutaneously or by venous cut-downs as necessary at the antecubital fossa of one arm. The tip of the injection catheter rested in the cephalic vein above the mid-portion of the upper arm. The withdrawal catheter extended via the median cubital vein into the axilla.

The subject was seated in a chair, and 10 minutes after a priming dose of ICG, sufficient to fill the catheter, a 15-ml sample of blood to be used as a zero-absorbancy reference (blank) and for standard curves was taken. Immediately afterward $12.5 \mathrm{mg}$ of ICG was injected from a calibrated 5-ml syringe. Thereafter, 3-ml samples of blood were taken at precisely timed intervals for 12 minutes after an initial 3- to 4-minute delay.

Ten minutes later the subject was positioned on the treadmill with the catheterized arm resting on an armboard to minimize support. Heart rate was monitored by electrocardiogram, and expired air was collected through a low resistance Collins "triple $\mathrm{j}$ valve" (resistance, $2 \mathrm{~cm} \mathrm{H} \mathrm{H}_{2} \mathrm{O}$ at $200 \mathrm{~L}$ per minute) into a balanced $350 \mathrm{~L}$ Collins spirometer connected to the valve by widelumen (13 inch) pipe and rubber tubing. Even at maximal ventilations $[150 \mathrm{~L}$ per minute, standard temperature, pressure, dry (STPD)] it was felt that resistance remained low enough to minimize increases in intrathoracic pressure above those normally occurring at such high ventilations. Expired gas samples were analyzed by the Haldane technique or the Scholander microtechnique, or both, with duplicates required to check within $0.05 \%$ for both oxygen and carbon dioxide.

Except at near maximal exercise, the subject walked on the treadmill at 3.5 miles per hour ( $\mathrm{mph}$ ) at various grades for $4 \frac{1}{2}$ minutes at which time the blood sample to serve as spectrophotometric blank was obtained. At the fifth minute of exercise $12.5 \mathrm{mg}$ of ICG was injected, and 3-ml blood samples were withdrawn every 2 minutes thereafter for 10 minutes. After exercise the subject rested 20 to 25 minutes, and the same procedure was repeated at a higher level of exercise. Two men repeated the same level. At higher levels of exercise, where subjects ran at $7 \mathrm{mph}$ on appropriate grades, which were exhausting in less than 15 minutes, the sample of blood to be used as a spectrophotometric blank was taken after 1 to $1 \frac{1}{2}$ minutes of exercise. Dye was then immediately injected, after which additional samples were taken every 1 or 2 minutes depending upon the anticipated duration of exercise.

Blood loss usually ranged from 90 to $120 \mathrm{ml}$ during a single experiment, and the largest single loss was $220 \mathrm{ml}$. The total volume of isotonic saline injected ranged from 100 to $150 \mathrm{ml}$. Initially the studies required that $6-\mathrm{ml}$ samples be taken so that a third level of exercise was not studied in those subjects. The men were given water ad libitum; no weight loss was observed during the experiment. No subject was studied again within 3 weeks after an experiment.

After withdrawal into heparinized syringes, blood samples were centrifuged at $1,000 \times g$ for 30 minutes and afterwards analyzed spectrophotometrically in a Beckman DU spectrophotometer at $805 \mathrm{~m} \mu$. Lipemic serum from two subjects who ate breakfast was cleared by ultracentrifugation $(1,000,000 \mathrm{~g}$-minutes $)$ to obtain clear serum below the suspended chylomicrons. A known dye concentration of approximately $3 \mathrm{mg}$ per $\mathrm{L}$, was prepared in a sample of plasma, and from it successive dilutions of 1.5 and $0.75 \mathrm{mg}$ per $\mathrm{L}$. This was done for each subject, using a sample of dye from the injection reservoir that contained approximately $75 \mathrm{mg}$ of dye in $30 \mathrm{ml}$ of solvent. The standards were read against the subject's plasma blank, and each blank was read against water.

Estimated hepatic blood flow (EHBF). Estimates of hepatic blood flow were obtained by the single-injection method described by Wiegand, Ketterer, and Rapaport (18) and Caesar and co-workers (15). A $120-\mathrm{cm}$ no. 6 , venous Cournand catheter was wedged into a right hepatic vein under fluoroscopic guidance. The catheter was retracted just sufficiently to allow free withdrawal of blood and yet remain well into the hepatic vein ( 3 to 5 $\mathrm{cm})$. Care was taken to see that the catheter tip remained in the hepatic vein during maximal respiratory excursions. When the catheter was in a wedged or nearly wedged position, a 2- to $3-\mathrm{ml}$ injection of saline produced right upper quadrant discomfort in all subjects; this procedure proved useful in determining the position of the catheter tip. A Cournand needle was placed in the radial artery, and an ICG injection catheter was introduced as described above. All catheters were in the same arm.

The studies were carried out exactly as those outlined above with two exceptions: resting measurements were conducted with all but two of the subjects supine; the injected dye dose was $25 \mathrm{mg}$ in subjects JA and GJ and 
$31.3 \mathrm{mg}$ in the remaining subjects. In no case was the exact quantity of dye injected known, since the weight of dye in several vials was found to vary from 25 to 29 mg. However, only differences in absorbancy between the two sampling sites and their changes with time are required for use of this method. Changes in plasma volume could be roughly estimated from the slope of ICG concentration extrapolated to zero time when variations in volume or concentration of injected dose were known not to occur.

Hepatic venous samples were half-drawn 10 to $15 \mathrm{sec}-$ onds after the mid-point in volume of arterial sampling. This was done to correct for the transit time of blood across the hepatic sinusoids. At the end of exercise the position of the catheter tip was again viewed by fluoroscopy as a second check on its position in the hepatic vein.

Hepatic a-v oxygen difference. Blood samples were taken simultaneously from the radial artery and hepatic vein immediately after the final resting and exercise ICG clearance sample. The oxygen content was determined by the manometric method of Van Slyke and Neill.

Calculations. Plasma ICG concentrations were plotted against time on a semilogarithmic scale from which the half-life $\left(t_{3}\right)$ of ICG in plasma and the disappearance rate constant or fractional clearance rate $(\mathrm{K})$ were derived. The constant $\mathrm{K}$ was calculated from $\log _{e} 2 / \mathrm{t}_{1}$ derived from the more familiar form $\log _{e} C_{1}-\log _{e} C_{2} / t_{1}-t_{2}$, when $t_{1}-t_{2}=t_{3}$ and represents the fraction of the total quantity of injected dye that disappears from the plasma in 1 minute, or alternatively, the fraction of the plasma volume cleared in 1 minute. The percentage of the resting value for ICG clearance is most simply expressed as $\left(t_{3 r} / t_{\text {lex }} \times 100\right)$, where $t_{3 \text { ex }}$ and $t_{3 r}$ represent exercise and resting values, respectively, for ICG half-life.

The arterial-hepatic venous plasma extraction ratio (E) was calculated from the form $\mathrm{A}_{\mathrm{Oa}}-\mathrm{A}_{\mathrm{Obv}} / \mathrm{A}_{\mathrm{Oa}}$, where $\mathrm{AO}_{\mathrm{a}}$ and $\mathrm{AOnv}_{\mathrm{nv}}$ are arterial and hepatic venous absorbancy (or concentration, since either may be used) extrapolated to zero time. Plasma clearance (milliliters per minute) was calculated from the disappearance rate constant $(\mathrm{K})$ times estimated plasma volume, or $45 \mathrm{ml}$ per $\mathrm{kg}$ times body weight, the $45 \mathrm{ml}$ per $\mathrm{kg}$ being selected from several sources (19). The EHPF was calculated from plasma clearance/E and the EHBF from EHPF/1hematocrit.

The percentage of the resting value for hepatic blood flow was also approximated from the following relationship: $\left(\mathrm{av}_{\mathrm{r}} / \mathrm{av}_{\mathrm{ex}} \times 100\right)$, where $\mathrm{av}_{\mathrm{r}}$ and $\mathrm{av}_{\text {ex }}$ are the hepatic a-v oxygen difference during rest and during exercise, respectively.

\section{Results}

Fractional clearance of ICG. The resting plasma clearance rate of ICG was in close agreement with the findings of others $(14,15,18,20)$. The mean $t_{1}$ was 3.0 minutes (range, 2.3 to 3.7 minutes), and the fractional clearance rate $(K)$

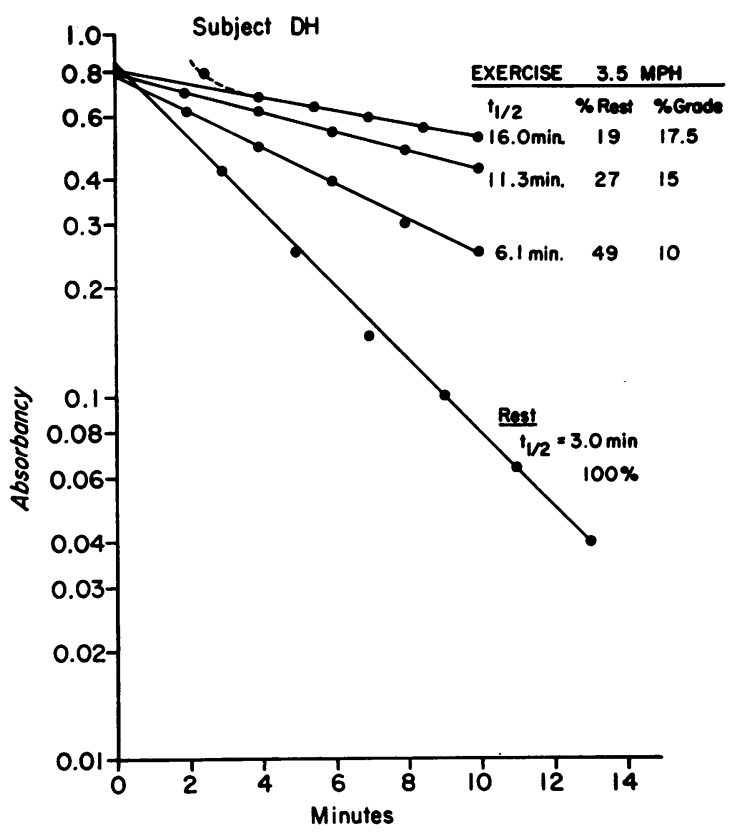

Fig. 1. Relationship of fractional clearance rate OF INDOCYANINE GREEN (ICG) FROM PERIPHERAL VENOUS BLOOD TO WORK INTENSITY. The change in absorbancy with time of ICG in plasma is shown for subject $\mathrm{DH}$ at rest and during treadmill exercise at 3.5 miles per hour (mph) on grades of 10,15 , and $17 \frac{1}{2} \%$. The halflife $\left(t_{\frac{1}{2}}\right)$ of each slope is specified in minutes and percentage of the resting $\mathrm{t}_{\frac{1}{2}}$, which was taken as $100 \%$. ICG was injected at the 5 th minute of exercise; time values on the abscissa are relative to the time of injection of ICG (at zero time).

was $23.5 \%$ per minute (range, 30.1 to $18.7 \%$ per minute). During exercise of various intensities (requiring from 26 to $97 \%$ of maximal oxygen intake) peripheral venous concentration again decreased linearly when plotted on a semilogarithmic scale against time (Figure 1), but the $t_{1}$ was prolonged over the resting values. The data from the clearance studies on 10 men are presented in Table I.

The distribution of fractional clearance rates of ICG expressed as percentage of resting values (taking rest as 100\%) is plotted against oxygen intake as percentage of maximal oxygen intake (Figure 2). The values represent a total of 47 observations from 10 subjects (Table I). The regression line was fitted by the method of least squares from the regression equation $y=-1.16 x$ +127.89 , where $y$ is the fractional clearance of ICG as percentage of the resting value and $x$ is 
the oxygen intake expressed as percentage of maximal oxygen intake. The slope of the line is -1.16 and the intercept, 127.89. The correlation coefficient is -0.89 and the SE of estimate is 9.9.

The prolongation of ICG clearance by the liver is inversely correlated with relative total oxygen intake expressed as the fraction of the maximal oxygen intake of which the individual is capable. However, when the ICG clearance is plotted against the absolute oxygen intake (milliliters per kilogram per minute), the correlation is diminished $(r=-0.77)$ (Figure 3 ) and the SE of estimate increased to 13.6. The regression equation is $y=-1.81 x+113.18$, with the exception that $x$ in this equation represents oxygen intake in milliliters per kilogram per minute.

In two instances, where work required 76 and $97 \%$ of maximal oxygen intake, the fractional clearance of ICG was only $19 \%$ of the resting value, the largest decrement in clearance observed.

The first study on JA followed by only 3 hours a very large, high-fat breakfast, whereas the second study adhered to the regular protocol. No large differences are noted in ICG clearance rates when the two studies are compared, therefore suggesting that the presence of food in the digestive tract does not influence hepatic clearance of ICG.

The agreement found in repeat determinations was usually close (Table I). Duplicate tests were carried out on JB on two separate occasions ( Table I). The four tests, all at $3.5 \mathrm{mph}$ on a $10 \%$ grade, showed ICG clearances that varied from 52 to $46 \%$ of the resting value with three at $46 \%$. Subject LJ was tested on three separate occasions. Despite repeated commands to this man, he leaned heavily on the support for the catheterized arm, thereby producing inadvertently a series of tests

TABLE I

Plasma clearance of indocyanine green during rest and mild to maximal exercise in normal upright men

\begin{tabular}{|c|c|c|c|c|c|c|c|c|c|}
\hline Subject & Age & $\mathrm{Wt}$ & $\mathrm{O}_{2}$ intake & $\begin{array}{c}\mathrm{O}_{2} \text { intake, } \\
\% \text { of } \\
\text { maximal }\end{array}$ & $\begin{array}{l}\text { Heart } \\
\text { rate }\end{array}$ & $t_{1}$ & $\mathrm{k}$ & $\begin{array}{c}\text { ICG } \\
\text { clearance, } \\
\% \text { of resting }\end{array}$ & $\begin{array}{c}\text { Maximal } \\
\mathrm{O}_{2} \text { intake }\end{array}$ \\
\hline \multirow{8}{*}{ J. B. } & $y r s$ & $k g$ & $\mathrm{ml} / \mathrm{kg} / \mathrm{min}$ & $\%$ & beats/min & $\min$ & $\min ^{-1}$ & $\%$ & $\mathrm{ml} / \mathrm{kg} / \mathrm{min}$ \\
\hline & \multirow[t]{7}{*}{33} & \multirow[t]{7}{*}{84} & Rest & & & 3.1 & 0.224 & & 41 \\
\hline & & & 31.7 & 77 & 165 & 6.2 & 0.112 & 50 & \\
\hline & & & 32.2 & 78 & 164 & 6.8 & 0.102 & 46 & \\
\hline & & & Rest* & & & 3.1 & 0.224 & & \\
\hline & & & 14.6 & 36 & & 3.4 & 0.204 & 91 & \\
\hline & & & 32.5 & 79 & & 6.7 & 0.103 & 46 & \\
\hline & & & 33.0 & 80 & & 6.7 & 0.103 & 46 & \\
\hline \multirow[t]{11}{*}{ J. L. } & \multirow[t]{11}{*}{19} & \multirow[t]{11}{*}{95.7} & Rest & & & 2.5 & 0.277 & & 43 \\
\hline & & & 28.9 & 67 & 188 & 5.6 & 0.124 & 42 & \\
\hline & & & 31.3 & 73 & 196 & 8.2 & 0.084 & 35 & \\
\hline & & & Rest* & & & 2.8 & 0.248 & & \\
\hline & & & 30.3 & 70 & 195 & 7.4 & 0.094 & 38 & \\
\hline & & & 30.7 & 72 & 198 & 8.2 & 0.084 & 34 & \\
\hline & & & 33.8 & 79 & 202 & 9.0 & 0.077 & 31 & \\
\hline & & & Rest* & & & 3.1 & 0.224 & & \\
\hline & & & 15.4 & 36 & 125 & 4.0 & 0.173 & 78 & \\
\hline & & & 23.6 & 54 & 152 & 4.0 & 0.173 & 78 & \\
\hline & & & 31.1 & 72 & 190 & 6.1 & 0.114 & 51 & \\
\hline \multirow[t]{7}{*}{ J. A. } & \multirow[t]{7}{*}{23} & \multirow[t]{7}{*}{74} & Rest & & & 3.0 & 0.231 & & 58 \\
\hline & & & 30.8 & 53 & 126 & 3.8 & 0.182 & 79 & \\
\hline & & & 40.0 & 69 & 147 & 4.8 & 0.144 & 62 & \\
\hline & & & Rest* & & & 3.4 & 0.204 & & \\
\hline & & & 14.8 & 26 & 83 & 3.4 & 0.204 & 100 & \\
\hline & & & 30.2 & 52 & 130 & 4.5 & 0.154 & 76 & \\
\hline & & & 37.4 & 65 & 143 & 5.6 & 0.124 & 58 & \\
\hline \multirow[t]{5}{*}{ M. S. } & \multirow[t]{5}{*}{21} & \multirow[t]{5}{*}{68.6} & Rest & & & \multirow{5}{*}{$\begin{array}{l}2.3 \\
3.5 \\
2.8 \\
4.0 \\
6.2\end{array}$} & \multirow{5}{*}{$\begin{array}{l}0.301 \\
0.198 \\
0.248 \\
0.173 \\
0.112\end{array}$} & & \multirow[t]{5}{*}{55} \\
\hline & & & 29.2 & 53 & 142 & & & 66 & \\
\hline & & & Rest* & & & & & & \\
\hline & & & 29.4 & 53 & 142 & & & 70 & \\
\hline & & & 37.2 & 68 & 168 & & & 45 & \\
\hline \multirow[t]{2}{*}{ D. H. } & \multirow[t]{2}{*}{21} & \multirow[t]{2}{*}{78} & Rest & & & 3.0 & 0.231 & & \multirow[t]{2}{*}{57} \\
\hline & & & 31.0 & 55 & 148 & 5.0 & 0.139 & 60 & \\
\hline
\end{tabular}


TABLE I-Continued

\begin{tabular}{|c|c|c|c|c|c|c|c|c|c|}
\hline Subject & Age & $\mathrm{Wt}_{\mathrm{t}}$ & $\mathrm{O}_{2}$ intake & $\begin{array}{c}\mathrm{O}_{2} \text { intake, } \\
\% \text { of of } \\
\text { maximal }\end{array}$ & $\underset{\text { rate }}{\text { Heart }}$ & $t_{4}$ & $\mathrm{k}$ & $\begin{array}{c}\text { IIG } \\
\text { clearance, } \\
\% \text { of resting }\end{array}$ & $\underset{\mathrm{O}_{2} \text { intake }}{\text { Maximal }}$ \\
\hline & $y r s$ & $\mathrm{~kg}$ & $\begin{array}{l}\mathrm{ml} / \mathrm{kg} / \min \\
31.2 \\
39.5 \\
\text { Rest* }^{*} \\
29.5 \\
40.0 \\
43.2\end{array}$ & $\begin{array}{l}\% \\
55 \\
72 \\
52 \\
70 \\
76\end{array}$ & $\begin{array}{c}\text { beals/min } \\
152 \\
175 \\
148 \\
181 \\
187\end{array}$ & $\begin{array}{r}\min \\
5.2 \\
9.8 \\
3.0 \\
6.1 \\
11.3 \\
16.0\end{array}$ & $\begin{array}{l}\min ^{-1} \\
0.133 \\
0.071 \\
0.231 \\
0.114 \\
0.061 \\
0.043\end{array}$ & $\begin{array}{r}\% \\
58 \\
31 \\
49 \\
27 \\
19\end{array}$ & $m l / k g / m i n$ \\
\hline L. R. & 33 & 77.6 & $\begin{array}{l}\text { Rest } \\
27.0 \\
34.8 \\
52.0 \\
\text { Rest* } \\
28.9 \\
38.4 \\
57.0 \\
\text { Rest* } \\
27.0 \\
34.7 \\
52.0\end{array}$ & $\begin{array}{l}47 \\
60 \\
90 \\
49 \\
65 \\
97 \\
47 \\
60 \\
90\end{array}$ & $\begin{array}{l}128 \\
157 \\
188 \\
140 \\
166 \\
188 \\
\\
136 \\
162 \\
188\end{array}$ & $\begin{array}{r}3.0 \\
3.2 \\
5.5 \\
11.0 \\
2.7 \\
4.1 \\
7.2 \\
14.0 \\
3.3 \\
3.7 \\
5.3 \\
9.6\end{array}$ & $\begin{array}{l}0.231 \\
0.216 \\
0.126 \\
0.063 \\
0.257 \\
0.169 \\
0.096 \\
0.050 \\
0.210 \\
0.187 \\
0.131 \\
0.072\end{array}$ & $\begin{array}{l}93 \\
55 \\
27 \\
\\
66 \\
38 \\
19 \\
\\
91 \\
63 \\
35\end{array}$ & 58 \\
\hline W. D. & 24 & 77 & $\begin{array}{l}\text { Rest } \\
30.2 \\
38.0 \\
\text { Rest* } \\
14.7 \\
29.3 \\
36.5\end{array}$ & $\begin{array}{l}60 \\
76 \\
29 \\
58 \\
73\end{array}$ & $\begin{array}{l}162 \\
186 \\
\\
120 \\
164 \\
184\end{array}$ & $\begin{array}{l}3.7 \\
6.8 \\
9.6 \\
3.0 \\
3.5 \\
5.1 \\
8.5\end{array}$ & $\begin{array}{l}0.187 \\
0.102 \\
0.072 \\
0.231 \\
0.198 \\
0.136 \\
0.082\end{array}$ & $\begin{array}{l}54 \\
39 \\
\\
86 \\
59 \\
35\end{array}$ & 50 \\
\hline L. J. & 23 & 78 & $\begin{array}{l}\text { Rest } \\
30.6 \\
37.1\end{array}$ & $\begin{array}{l}66 \\
81\end{array}$ & $\begin{array}{l}175 \\
193\end{array}$ & $\begin{array}{r}2.8 \\
5.2 \\
11.0\end{array}$ & $\begin{array}{l}0.248 \\
0.133 \\
0.063\end{array}$ & $\begin{array}{l}54 \\
25\end{array}$ & 46 \\
\hline P. W. & 22 & 74.6 & $\begin{array}{l}\text { Rest } \\
30.1 \\
38.5\end{array}$ & $\begin{array}{l}46 \\
60\end{array}$ & $\begin{array}{l}115 \\
147\end{array}$ & $\begin{array}{l}2.7 \\
3.6 \\
4.7\end{array}$ & $\begin{array}{l}0.257 \\
0.192 \\
0.147\end{array}$ & $\begin{array}{l}75 \\
58\end{array}$ & 65 \\
\hline R. L. & 37 & 86.1 & $\begin{array}{l}\text { Rest } \\
12.3 \\
25.6\end{array}$ & $\begin{array}{l}30 \\
63\end{array}$ & $\begin{array}{r}94 \\
146\end{array}$ & $\begin{array}{l}3.0 \\
3.4 \\
4.6\end{array}$ & $\begin{array}{l}0.231 \\
0.204 \\
0.150\end{array}$ & $\begin{array}{l}88 \\
65\end{array}$ & 40 \\
\hline
\end{tabular}

${ }^{*}$ Repeat studies 3 to 4 weeks after the previous study.

that required approximately the same amount of oxygen despite the increases in percentage of grade of the treadmill. With the exception of the final value, as listed in Table $I$, the clearance slopes are a fairly sensitive indicator of the severity of exercise. Although subject LR was studied on three occasions, the second study produced clearance rates that were markedly different from those obtained in the first and third studies (Table I). It is not understood why these discrepancies occurred. It is only known that this subject "felt different" during the second study.

Volume distribution of ICG. The volume distribution of ICG in 17 men averaged $49.5 \mathrm{ml}$ per $\mathrm{kg}$ body weight (range, 35 to $62 \mathrm{ml}$ per $\mathrm{kg}$ ). The average change in the volume distribution of ICG with exercise on the treadmill set at $3.5 \mathrm{mph}$ and a $10 \%$ grade was $12.6 \%$ (the range for 14 men was 0 to $27 \%$ ).

Estimated hepatic blood flow $(E H B F)$. Estimates of hepatic blood flow demonstrated that the decrease in ICG clearance (Figure 1) observed during exercise is primarily the result of decreased EHBF and not a decrease in extraction ratio. The values from seven men are presented in Table II. The curves and calculations for a single subject at rest and during exercise are shown in Figure 4.

The mean resting $\mathrm{EHBF}$ was $1,614 \mathrm{ml}$ per minute, whereas during exercise of various intensities, EHBF fell to values ranging from 820 to $390 \mathrm{ml}$ per minute. The average extraction ratio at rest was 0.77 (range, 0.47 to 0.94 for 7 observations), whereas the average value during ex- 


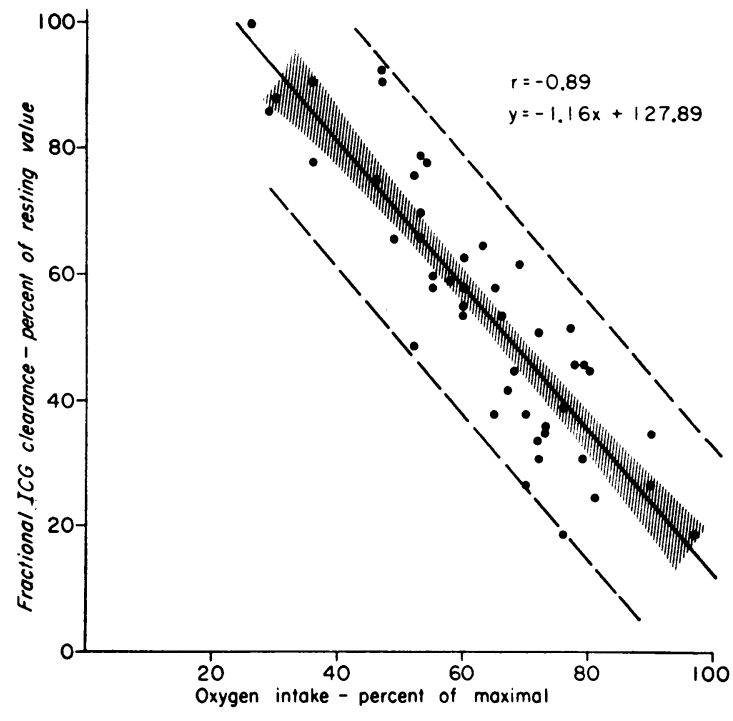

Fig. 2. Correlation between fractional (Learance RATE OF ICG AS PERCENTAGe OF THE RESTING VAlue (100\%) AND OXYGEN INTAKE AS PERCENTAGE OF MAXIMAL OXYGEN INTAKE. About the least squares regression line are $a$ ) the $95 \%$ confidence interval (shaded area) for the true mean value of $y$ (ICG clearance) for a given value of $x$ (oxygen intake) from the regression equation $y=-1.16 x+127.89$ and $b$ ) the wider $95 \%$ confidence interval for the true $y$-value of an individual having the given $x$-value, indicated by the dashed lines.

ercise of various intensities was 0.84 (range, 0.70 to 0.95 for 12 observations). In three subjects small decreases in the extraction ratio of ICG were observed during exercise, and in one of these men (MM) a $22 \%$ fall in extraction ratio was noted at the highest level of exercise studied (20\% grade, $3.5 \mathrm{mph}$ ). Due to the decrease in plasma volume that occurs during exercise, percentage changes in EHBF still agreed closely with the percentage changes in ICG clearance rate in those where extraction ratio did decrease. As expected, in the five subjects who showed increased extraction of ICG during exercise, the estimates of the decreases in hepatic blood flow using only the change in the peripheral venous disappearance rate of ICG underestimated the measured decreases in EHIBF.

The average difference between a) percentage change in the fractional clearance rate of ICG and $b$ ) percentage change in EHBF with exercise was $8.2 \%$ (range, 20 to $-5 \%$ ) with $b$ being greater than $a$. There was, therefore, a tendency for the peripheral sampling method to slightly underestimate the extent to which EHBF decreased during exercise.

Hepatic a-v oxygen difference. In the five subjects used for measurements of arterial and hepatic venous oxygen content, a marked widening of the hepatic a-v oxygen difference occurred during exercise. The percentage change in hepatic blood flow estimated from $\mathrm{av}_{\mathrm{r}} / \mathrm{av}_{\mathrm{ex}} \times 100$ closely paralleled the percentage change in ICG clearance rate and EHBF. The mean difference between percentage change from rest to exercise in ICG clearance slope and the percentage change in hepatic a-v oxygen difference was $8.6 \%$ with the latter being higher (range, 19 to $-1 \%$ ). The mean difference between $a$ ) the percentage change from rest to exercise in $\mathrm{EHBF}$ and $b$ ) percentage change in hepatic a-v oxygen difference from rest to exercise was $2 \%$ (range, 10 to $-12 \%$ ), the change in $a$ being greater than $b$. Thus, the change in EHBF with exercise was also very closely paralleled by changes in hepatic a-v oxygen difference. In the case of $\mathrm{RC}$, whose $\mathrm{EHBF}$ decreased to $16 \%$ of the resting value during exercise, which was severe for this subject, the hepatic venous oxygen content fell from $16.00 \mathrm{ml}$ per $100 \mathrm{ml}$ at rest to $0.99 \mathrm{ml}$ per $100 \mathrm{ml}$ during exercise.

The estimated mean splanchnic oxygen uptake at rest (Table II) was $68 \mathrm{ml}$ per minute (range, 104 to $41 \mathrm{ml}$ per minute), and during exercise the mean value was $69 \mathrm{ml}$ per minute (range, 87 to $44 \mathrm{ml}$ per minute).

The product of arterial oxygen content during exercise and the volume of blood shunted away from the hepatic bed (i.e., resting less exercise $\mathrm{EHBF}$ ) provides an estimate of increased oxygen transport to other regions. The values (Table II) ranged from 128 to $429 \mathrm{ml}$ oxygen per minute.

\section{Discussion}

In an excellent discussion of the concept of hepatic clearance, Fauvert (21) summarizes the basic assumptions inherent in clearance tecliniques. Most important is the nature of the substance to be cleared, since the measurement of organ clearance, i.e., the virtual volume of plasma completely cleared of that substance in 1 minute, is valid only when that substance is cleared from the blood exclusively by that organ. Numerous publications 


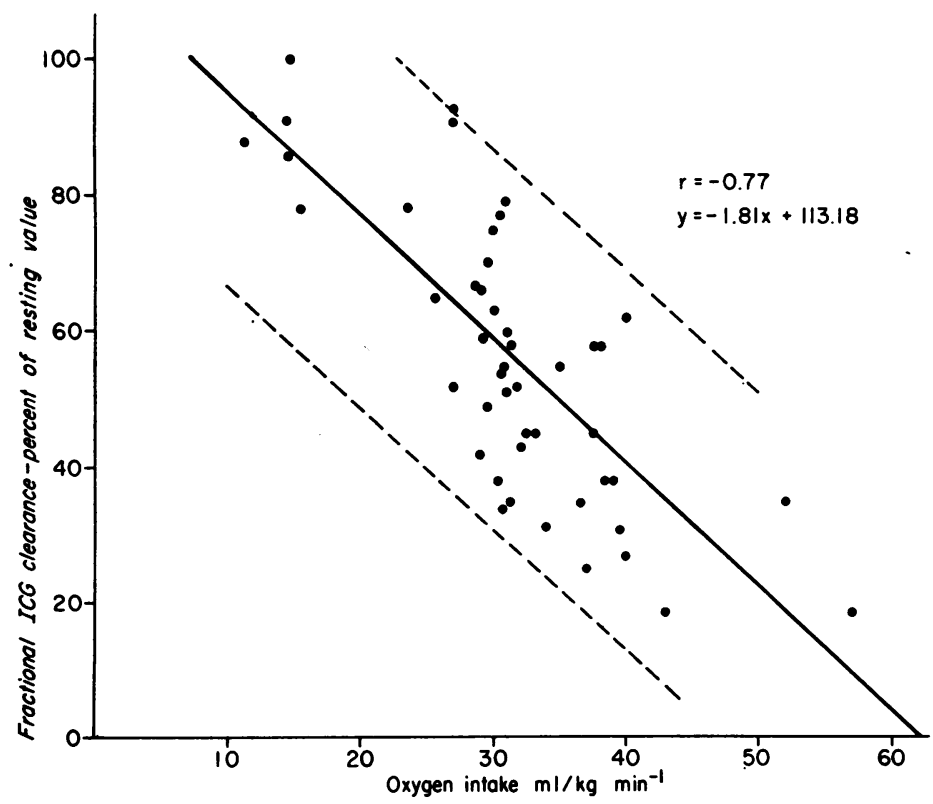

Fig. 3. Correlation between fractional clearance rate of ICG AS PERCENTAGe OF THE RESTING VALUe (100\%) AND OXYGEN INTAKE IN MILLILITERS PER KILOGRAM PER MINUTE. About the least squares regression line is shown the $95 \%$ confidence interval (dashed lines) for the true value for $y$ (ICG clearance) for an individual having the given values of $x$ (oxygen intake) from the regression equation $y=-1.81 x+113.18$.

have shown that in dogs $(13,22)$, in humans (1315 ), and in other animals (13) ICG, unlike BSP, is cleared exclusively by the liver. Indeed, the peripheral clearance of ICG has been shown to be a sensitive and reliable index of hepatic function in resting man $(14,15,18,20)$.

During exercise, however, there are possible extrahepatic routes of removal of ICG. The dye combines immediately with serum albumin, which passes rapidly with other proteins through capillary walls during exercise (23). However, according to De Lanne, Barnes, and Brouha (24) the filtered albumin is rapidly returned to the circulation because of accelerated lymph circulation during exercise, precluding any net loss of albumin from the blood. The result is an extrahepatic circulation of ICG that is probably quantitatively very small. To offset the initial changes in albumin concentration, in plasma volume, and in plasma optical density (25), a period of $4 \frac{1}{2} \mathrm{~min}$ utes after the start of exercise and before the pre-injection plasma blank was drawn was provided in the experimental design. The major vol- ume shifts occur within a 5-minute period during moderate to heavy exertion $(26,27)$. The uppermost slope in Figure 1 ( $17.5 \%$ grade, $3.5 \mathrm{mph}$ ) indicates an initial nonlinearity of the ICG disappearance slope if injection or sampling, or both, are started too soon after the onset of exercise. The fact that the disappearance of ICG follows first-order kinetics, after the initial alterations in volume and concentration, argues against the possibility of either significant extrahepatic circulation or of changing hepatic flow with time under these experimental conditions.

Although no ICG is lost into urine during resting measurements (14-16), during exercise considerable quantities of albumin may be lost in urine (28). In checking urine samples of two subjects at the end of a study, no evidence of the dye was found in urine that was made up to a $5 \%$ solution with human serum albumin to stabilize any ICG $(14,15)$.

Although the large and consistent changes during exercise indicate a marked impairment of hepatic capacity to remove ICG from blood, there is 
I. B. ROWELL, J. R. BLACKMON, AND R. A. BRUCE.

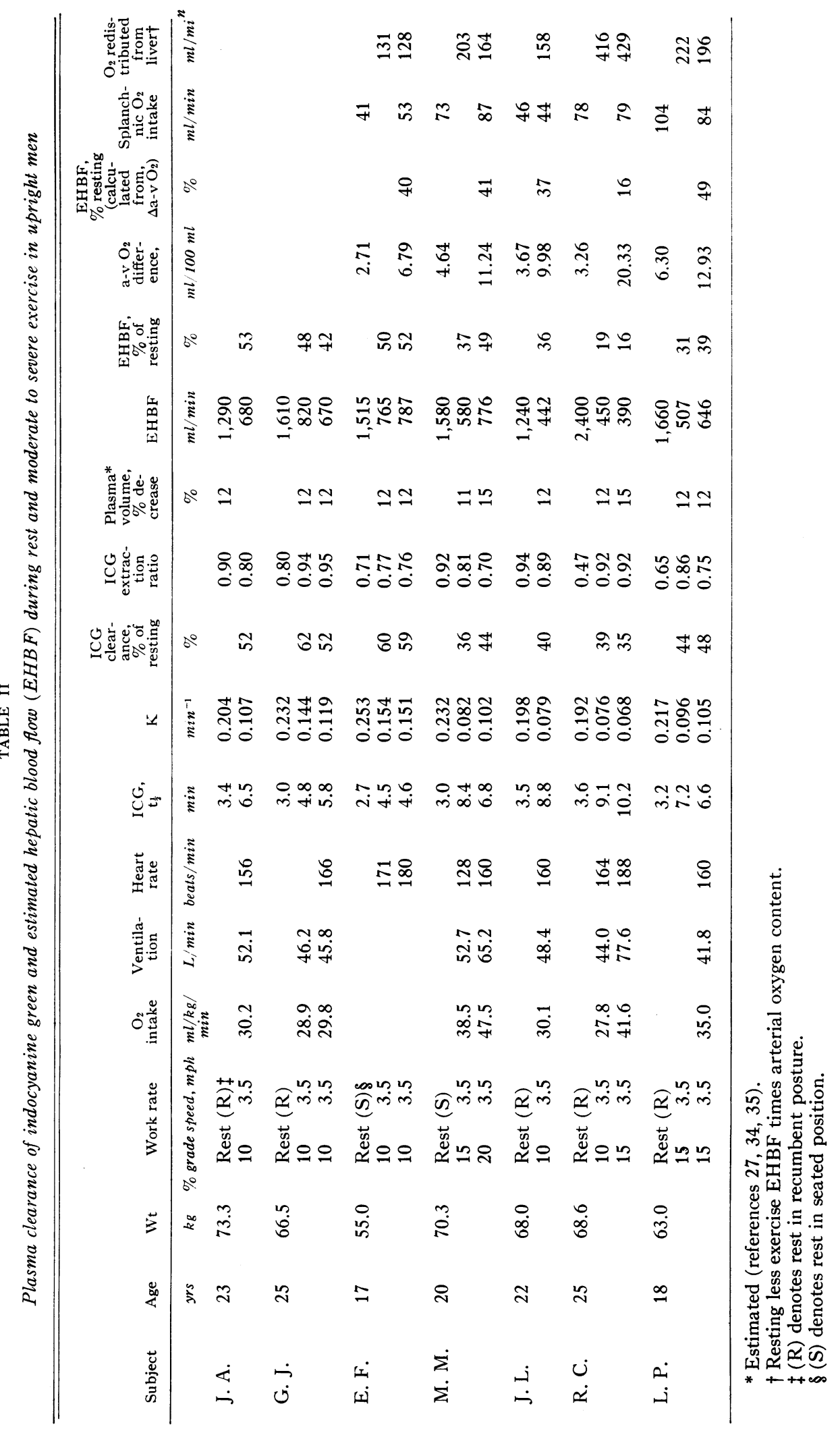




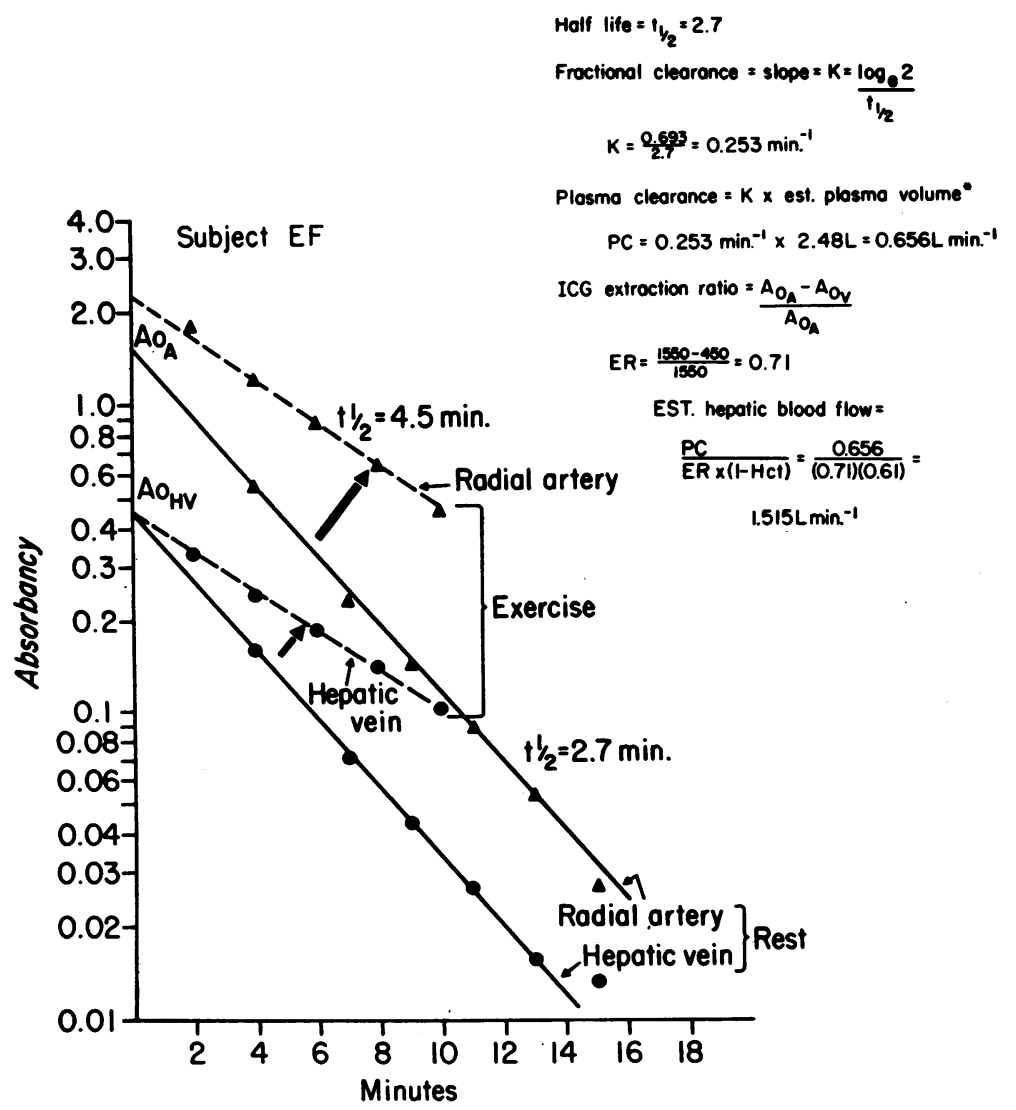

Fig. 4. Peripheral arterial and hepatic venous plasma clearance OF ICG DURING REST AND EXERCISE. The change in absorbancy with time of ICG in plasma from the two sampling sites is shown for subject EF seated at rest (solid lines) and during treadmill exercise at $3.5 \mathrm{mph}$ on a $10 \%$ grade (dashed lines). The method of calculating estimated hepatic blood flow (EHBF) is shown. Plasma volume was taken as $45 \mathrm{ml}$ times weight in $\mathrm{kg}$. During exercise EHBF and extraction efficiency for ICG changed from $1,515 \mathrm{ml}$ per minute and $71 \%$ (at rest) to $765 \mathrm{ml}$ per minute and $77 \%$, respectively.

no way of differentiating from these data any changes due to hemodynamic factors from those due to altered hepatic cellular function. By definition, clearance of a substance from any organ depends upon blood flow through the organ and the removal efficiency (extraction ratio) for that substance.

There are reasons for assuming that the hepatic extraction efficiency for a substance such as ICG would increase during severe upright exercise, since alterations such as abdominal compression $(29,30)$, orthostasis $(30,31)$, syncope (31), and mild supine exercise $(7,8)$, which decrease hepatic blood flow, increase the extraction efficiency for BSP. This is logical, since blood remains for a longer period in the hepatic sinusoids. Brauer (32) has shown in the isolated rat liver that BSP extraction efficiency bears an inverse relationship to tissue perfusion rate. Even generalized hepatic ischemia has little influence on BSP extraction efficiency $(29,32)$. It is reasonable to assume that ICG and BSP are handled similarly, for despite their removal by different hepatic mechanisms (14) the two substances are cleared and extracted similarly with respect to time in the same individual with impaired hepatic function $(14,15)$.

Experimentally, however, extraction efficiency is difficult to measure accurately. The major difficulty is one of obtaining hepatic venous sam- 


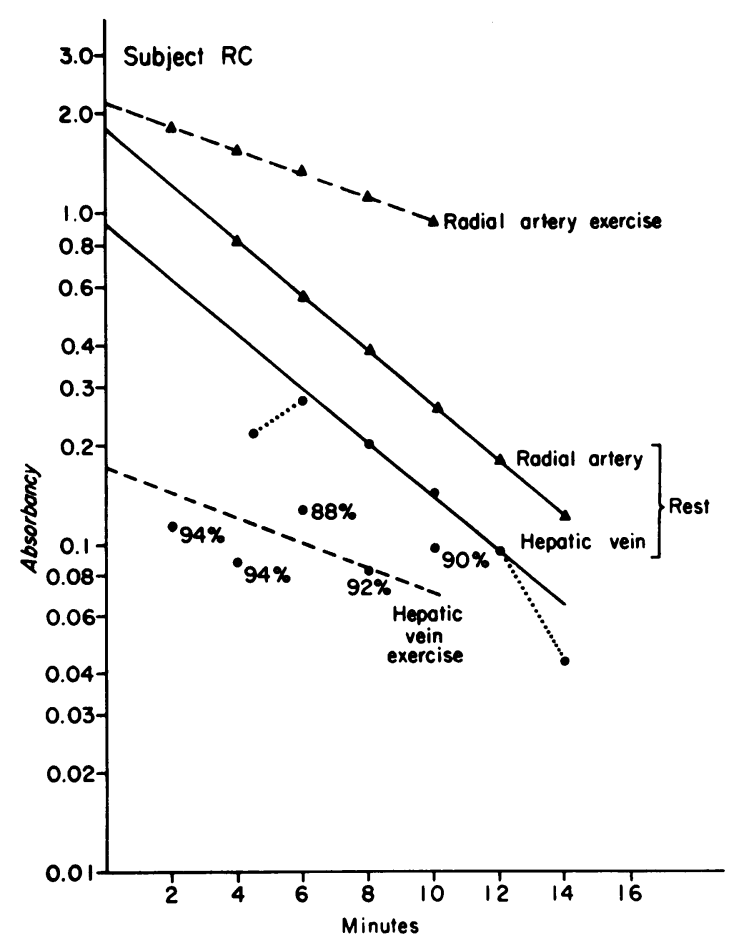

Fig. 5. Peripheral arterial and hepatic venous PLASMA ClEARANCE OF ICG DURING REST AND EXERCISE. The change in absorbancy with time of ICG in plasma is shown for subject $\mathrm{RC}$ lying at rest (solid lines) and during treadmill exercise at $3.5 \mathrm{mph}$ on a $10 \%$ grade (dashed lines). Irregularities in hepatic venous levels of ICG during rest and exercise probably result from an excessively deep hepatic venous wedge (see text). Numerals about the lowermost dashed line represent extraction efficiency at each point during exercise.

ples. Since "hepatic venous blood" does not exist as a pooled volume representing the mixed contents of all lobes of the liver, but rather as separate pools released into their own venous systems, truly representative samples cannot be obtained. Bradley, Ingelfinger, Bradley, and Curry (33) have shown that the variation in BSP extraction efficiency at different locations in the same liver was as great as $20 \%$ in two cases. Another important problem is the variation in hepatic venous pressure and instantaneous flow introduced by respiration. Bradley and co-workers (33) noted reflux of caval blood during heavy breathing, and they stressed the necessity of quiet breathing during the sampling period. Brauer (32) reports recent cineangiographic evidence that during quiet respiration, hepatic venous outflow is arrested during inspiration, and is maximal just before peak expiratory excursion of the diaphragm. Indeed, even regurgitation of vena caval blood into hepatic veins occurs in some animals during inspiration (32), indicating a positive pressure gradient from the cava to hepatic vein at this time. Also position of the catheter is critical. Although retraction of the catheter tip increases greatly the risk of caval reflux into the catheter, advancement of the catheter to wedge position in a hepatic vein results in increased oxygen content of withdrawn blood (32). In this situation deflection of portal flow to adjacent regions results, as evidenced by detection of substances injected into the hepatic artery and failure to detect all but minute quantities injected into the portal route (32).

Regardless of whether the indicator is ICG or oxygen, the extraction efficiency is likely to be underestimated either when the catheter is too deeply wedged, or when it is too close to the caval orifice of the vein. The irregularity of hepatic venous concentration of ICG seen in several of our experiments (Figure 5) may have been the result of one or several of the problems stated above. The results from $\mathrm{RC}$ are a case in point. This subject showed an extraction efficiency for ICG while at rest that was very low, $47 \%$ (Figure 5). If a line parallel to the resting arterial slope were drawn through the first and final points where extraction at rest was greater, efficiency would increase from 47 to $72 \%$. However, the four points through which the slope was drawn show the same ICG concentration-time relationship that was found in arterial blood. This would make a random dilution from caval blood seem unlikely. The variation in extraction efficiency during rest and exercise might be accounted for by an excessively deep hepatic venous wedge, since sampling from this individual was frequently difficult. Despite this variation, however, there is little question that hepatic extraction of ICG was higher during exercise; (extraction efficiency ranged from 88 to $94 \%$ and averaged $92 \%$ ). A similar problem, although less marked, occurred during the first exercise study with LP and was resolved in the same manner. After slight retraction of the catheter, a repeat exercise study with the same work intensity provided a perfect set of slopes and close agreement with the EHBF of the first test. Studies on two other subjects were dis- 
carded because of obvious dilution of hepatic venous blood with caval blood.

The single injection technique has never been employed for the study of EHBF during exercise, but has been employed at rest, where it was shown to provide results corresponding closely to those obtained by the constant infusion technique in the same individuals $(15,20)$. In theory neither is superior, since one simply provides an integral (constant infusion) and the other a differential. The single injection technique has the advantage of requiring only the fractional clearance rate of ICG and the extraction efficiency for the dye. Also no long period for equilibration of dye is needed, and repeated determinations are possible with less risk of saturating the hepatic extraction mechanism for the dye. The method has the disadvantage of requiring that plasma volume be known. As in earlier studies (33) a figure representative of the per kilogram plasma volume was selected, since the principle aim of this study was to assess only changes in hepatic blood flow. Accordingly, it became necessary to add an additional approximation to this study; namely, the decrease in plasma volume resulting from exercise. It was possible to select from a literature source (34) carefully determined values of plasma volume decreases during an intensity of exercise ( $8.6 \%$ grade, $3.5 \mathrm{mph}$ ) close to the lowest intensity employed in this study (10\% grade, 3.5 $\mathrm{mph}$ ). Additional investigations provided clues as to probable decreases at higher levels of exercise $(27,34,35)$. Despite the rather close agreement in this study of the mean value for plasma volume with the findings of others (19) and, as well, the average change with exercise $(10 \%$ grade, $3.5 \mathrm{mph}$ ) (34), the wide variability observed (due principally to variation in the injected dose of dye), discouraged the individual use of this estimator of plasma volume or changes therein. Others, however, have shown the validity of estimates of plasma volume using a single injection of ICG $(15,18)$.

Despite the problems inherent in the methods, particularly during severe upright exercise, the results (i.e., changes in $\mathrm{EHBF}$, hepatic extraction efficiency, and hepatic a-v oxygen difference) of this study were consistent during rest $(14,15,18$, 20 ) and mild exercise with the findings of Brad- ley (7) and Wade and associates (8). In addition, derived values for splanchnic oxygen uptake during rest and exercise agreed quite closely with the findings of these investigators $(7,8)$. Furthermore, they supported the conclusion of Wade and his colleagues that splanchnic oxygen uptake is not significantly altered during exercise. Parenthetically, the latter finding may provide some physiologic basis for the time-honored procedure of assuming an unaltered metabolic rate during exercise for tissues that remain essentially at rest. This tacit assumption is inherent in the estimation of oxygen debt that is calculated from the difference between total recovery oxygen uptake less the pre-exercise resting oxygen consumption.

Although the exclusive extraction of ICG by the liver restricts its use to measurement of hepatic rather than total splanchnic blood flow, in the absence of portacaval shunting of blood the splanchnic flow is also estimated. Such shunts are known to exist in normal man (36), but quantitatively may be in the order of $10 \%$ of the total splanchnic blood flow (37). On the contrary, oxygen is removed by extrahepatic, portal organs; therefore, a change in hepatic a-v oxygen difference does not necessarily reflect a change in hepatic blood flow, particularly if portacaval shunting is quantitatively significant. Since the changes in hepatic a-v oxygen difference agreed on the average to within $2 \%$ of changes in $\mathrm{EHBF}$, portacaval shunting was not significantly altered in proportion to total portal flow during exercise, and therefore changes in $\mathrm{EHBF}$ must be closely equivalent to changes in total splanchnic blood flow.

On the basis of the findings in this study, it is concluded that large decreases in EHBF and total splanchnic blood flow do occur in normal men during moderate to severe upright exercise. Because of the difficulty in obtaining hepatic venous blood samples, particularly when ventilatory rates are high, EHBF measurements were not attempted during exercise either at or near the level of maximal oxygen intake. However, since the decreases in fractional clearance rates of ICG during sub-maximal exertion are usually rather close approximations of the measured decreases in $\mathrm{EHBF}$, and in fact frequently underestimate them, it is reasonable to assume that very large decreases (approximately 80\%) in hepatic blood 
TABLE III

The cardiac output at a fixed level of oxygen intake that represents varying proportions of maximal oxygen intake in six sedentary men before and after physical conditioning and in four endurance athletes* and the relationship to the predicted EHBF

\begin{tabular}{|c|c|c|c|c|}
\hline Subject & $\mathrm{O}_{2}$ intake* & $\begin{array}{l}\mathrm{O}_{2} \text { intake, } \\
\% \text { of maximal* }\end{array}$ & $\begin{array}{l}\text { Mean cardiac* } \\
\text { output }\end{array}$ & $\underset{\text { resting }}{\mathrm{EHBF}} \%$ of \\
\hline & $\mathrm{ml} / \mathrm{kg} / \mathrm{min}$ & $\%$ & $L, \min$ & $\%$ \\
\hline Six sedentary men (ages, 18-24 yrs) & $28.5 \pm 1.3$ & 58.5 & $17.5 \pm 3.2 \ddagger$ & 60 \\
\hline $\begin{array}{l}\text { Same six men after } 3 \text { months of physical } \\
\text { training }\end{array}$ & $28.5 \pm 1.3$ & 50.1 & $17.2 \pm 2.0 \ddagger$ & 70 \\
\hline Four endurance athletes (ages, $18-21$ yrs) & $28.5 \pm 1.3$ & 45.6 & $17.4 \S$ & 75 \\
\hline
\end{tabular}

* Reference 39.

$\dagger$ Predicted from Table 1 .

$\ddagger$ Mean and SD of 36 measurements.

$\S$ Mean of 24 measurements.

flow occur during maximal exercise. The observation of maximal decreases of $81 \%$ in ICG clearance and $84 \%$ in $\mathrm{EHBF}$ concurs with the estimate made by Wade and Bishop (3), who extrapolated their data from mild to moderate supine exercise to estimated maximal levels. This was also confirmed by the observation of a decrease in hepatic blood flow of approximately $80 \%$ (estimated from the increase in hepatic a-v oxygen difference) in a patient with rheumatic heart disease during supine exercise that maximally taxed the circulatory adaptations to exertion of this patient (11).

An interesting analogy exists between the endurance athlete, the sedentary man, and the cardiac patient. Although their maximal work capacities are markedly different, each shows very similar alterations in the partitioning of left ventricular output for distribution to the hepatic portal system, and, quite likely, to other vascular beds also (3). The levels of work or metabolism, or both, at which these changes in hepatic blood flow become very marked are closely related to the proportion of maximal oxygen consumption of the particular individual, rather than to the absolute level of oxygen intake or cardiac output, although the latter has not been examined in patients with cardiac impairment.

The relationship between ICG disappearance rate (as percentage of resting) and oxygen intake (milliliters per kilogram per minute) would be considerably less evident than it appears in Figure 3 were a larger number of endurance athletes with high values of maximal oxygen intake included. For example, MM (Table II) had a maximal oxygen intake of $75.3 \mathrm{ml}$ oxygen per $\mathrm{kg}$ per minute. At an oxygen uptake of $47.5 \mathrm{ml}$ per $\mathrm{kg}$ per minute, which exceeded the maximal value for four men (Table I), the decrease in EHBF for this subject was only $51 \%$.

Despite the marked differences between athletes and sedentary men in EHBF at a given level of submaximal aerobic metabolism (expressed per unit of body weight), the cardiac output is the same for the two types of individuals (Table III) (38-40). Thus, changes in EHBF with exercise are not related to differences in total blood flow in the two types of individuals, but rather to the proportional demands for oxidative metabolism.

The responsible mechanism(s) for these changes in EHBF during exertion is unknown. There are in addition, however, other physiologic changes that are closely correlated to the relative oxygen intake. For example, during levels of exertion requiring approximately $50 \%$ of maximal oxygen intake, the following changes occur: Blood lactic acid concentration (41) and respiratory quotient (42) begin to show a marked rise, and heart rate (in sedentary men) (42) breaks from a linear to asymptotic relationship to oxygen intake. These alterations may be concurrent with the onset of anaerobiosis in exercising skeletal muscles that develops as work intensity is increased.

It is also concluded from this study that interpretation of circulatory and other changes relative to a level of aerobic metabolism are meaningful only when this metabolic rate is expressed as the proportion of the maximal oxygen intake of which each individual is capable. In this way the circulatory and metabolic response to a fixed task can be meaningfully compared when individuals 
of widely varying maximal oxygen intake are studied.

\section{Summary}

The fractional clearance rate of indocyanine green (ICG) was determined from peripheral venous samples during rest and upright exercise requiring from 26 to $97 \%$ of maximal oxygen intake. An inverse linear relationship $(r=-0.89)$ was observed between fractional ICG clearance rate as percentage of the resting value and oxygen intake only when the latter was expressed as percentage of maximal oxygen intake.

To test the validity of this procedure as a means of assessing alterations in hepatic blood flow with exertion, the fractional clearance rate and hepatic extraction efficiency for ICG and estimated hepatic blood flow (EHBF) were determined in seven men during rest and at one or two rates of work.

The percentage change in ICG clearance underestimated percentage changes in $\mathrm{EHBF}$, on the average, by $8.2 \%$. Percentage changes in EHBF agreed, on the average, to within $2 \%$ of corresponding changes in hepatic arteriovenous (a-v) oxygen difference.

It was concluded that large decreases, in excess of $80 \%$, in EHBF occur in upright man during severe exertion. The magnitude of change in blood flow varied inversely with relative rather than absolute oxygen intake at all rates of work where relative oxygen intake is defined as the proportion of maximal oxygen intake.

\section{Acknowledgments}

The assistance of Drs. John Mazzarella and Robert Lamppert during numerous catheterization procedures and the technical assistance of Miss Julie Drinkard, Mrs. Eric Merrifield, and Mr. Philip Weiser are gratefully acknowledged. We also thank Drs. E. J. Masoro and Wade Volwiler for their critical evaluation of this manuscript.

\section{References}

1. Krogh, A. The regulation of the supply of blood to the right heart. Skand. Arch. Physiol. 1912, 27, 227.

2. Bock, A. V., C. Vancaulaert, D. B. Dill, A. Fölling, and L. M. Hurxthal. Studies in muscular activity. III. Dynamical changes occurring in man at work. J. Physiol. (Lond.) 1928, 66, 136.

3. Wade, O. L., and J. M. Bishop. Cardiac Output and Regional Blood Flow. Oxford, Blackwell Scientific Publications, 1962, pp. 87, 107.
4. Herrick, J. F., J. H. Grindlay, E. J. Baldes, and F. C. Mann. Effect of exercise on the blood flow in the superior mesenteric, renal and common iliac arteries. Amer. J. Physiol. 1940, 128, 338.

5. Rushmer, R. F., D. L. Franklin, R. L. Van Citters, and O. A. Smith. Changes in peripheral blood flow distribution in healthy dogs. Circulat. Res. 1961, 9, 675 .

6. Sjöstrand, T. The regulation of the blood distribution in man. Acta physiol. scand. 1952, 26, 312.

7. Bradley, S. E. Hepatic blood flow. Effect of posture and exercise upon blood flow through the liver in Transactions of the Seventh Conference on Liver Injury. New York, Josiah Macy, Jr., Foundation, 1948, p. 53.

8. Wade, O. L., B. Combes, A. W. Childs, H. O. Wheeler, A. Cournand, and S. E. Bradley. The effect of exercise on the splanchnic blood flow and splanchnic blood volume in normal man. Clin. Sci. 1956, 15, 457.

9. Lowenthal, M., K. Harpuder, and D. Blatt. Peripheral and visceral vascular effects of exercise and postprandial state in supine position. J. appl. Physiol. 1952, 4, 689.

10. Bishop, J. M., K. W. Donald, S. H. Tayior, and P. N. Wormald. Changes in arterial-hepatic venous oxygen content difference during and after supine leg exercise. J. Physiol. (Lond.) 1957, 137, 309.

11. Bishop, J. M., K. W. Donald, and O. L. Wade. Changes in the oxygen content of hepatic venous blood during exercise in patients with rheumatic heart disease. J. clin. Invest. 1955, 34, 1114.

12. Reeves, J. T., R. F. Grover, G. F. Filley, and S. G. Blount, Jr., Circulatory changes in man during mild supine exercise. J. appl. Physiol. 1961, 16, 279.

13. Hunton, D. B., J. L. Boolman, and H. N. Hoffman. Studies of hepatic function with indocyanine green. Gastroenterology 1960, 39, 713.

14. Cherrick, G. R., S. W. Stein, C. M. Leevy, and C. S. Davidson. Indocyanine green: observations on its physical properties, plasma decay, and hepatic extraction. J. clin. Invest. 1960, 39, 592.

15. Caesar, J., S. Shaldon, L. Chiandussi, L. Guevara, and S. Sherlock. The use of indocyanine green in the measurement of hepatic blood flow and as a test of hepatic function. Clin. Sci. 1961, 21, 43.

16. Bruce, R. A., J. R. Blackmon, J. W. Jones, and G. Strait. Exercise testing in adult normal subjects and cardiac patients. Pediatrics (suppl.) 1963, 32, 742.

17. Taylor, H. L., E. Buskirk, and A. Henschel. Maximal oxygen intake as an objective measure of cardio-respiratory performance. J. appl. Physiol. 1955, 8, 73. 
18. Wiegand, B. D., S. G. Ketterer, and E. Rapaport. The use of indocyanine green for the evaluation of hepatic function and blood flow in man. Amer. J. dig. Dis. 1960, 5, 427.

19. Gregersen, M. I. Blood volume, hemorrhage, and shock in Medical Physiology, 11th ed., P. Bard, Ed. St. Louis, C. V. Mosby, 1961, p. 280.

20. Reemtsma, K., G. C. Hottinger, A. C. DeGraff, Jr., and $\mathrm{O}$. Creech, Jr. The estimation of hepatic blood flow using indocyanine green. Surg. Gynec. Obstet. $1960,110,353$.

21. Fauvert, R. E. The concept of hepatic clearance. Gastroenterology 1959, 37, 603.

22. Ketterer, S. G., B. D. Wiegand, and E. Rapaport. Hepatic uptake and biliary excretion of indocyanine green and its use in estimation of hepatic blood flow in dogs. Amer. J. Physiol. 1960, 199, 481.

23. Keys, A., and H. L. Taylor. The behavior of the plasma colloids in recovery from brief severe work and the question as to the permeability of the capillaries to proteins. J. biol. Chem. 1935, 109, 55.

24. De Lanne, R., J. R. Barnes, and L. Brouha. Changes in concentration of plasma protein fractions during muscular work and recovery. J. appl. Physiol. 1958, 13, 97.

25. Ebert, R. V., and E. A. Stead, Jr. An error in measuring changes in plasma volume after exercise. Proc. Soc. exp. Biol. (N. Y.) 1941, 46, 139.

26. Holmgren, A. Circulatory changes during muscular work in man, with special reference to arterial and central venous pressures in the systemic circulation. Scand. J. clin. Lab. Invest. 1956, 8, (suppl. 24), 1.

27. Kaltreider, N. L., and G. R. Meneely. The effect of exercise on the volume of the blood. J. clin. Invest. $1940,19,627$.

28. Nedbal, J., and V. Seliger. Electrophoretic analysis of exercise proteinuria. J. appl. Physiol. 1958, 13, 244.

29. Selkurt, E. E. Effect of acute hepatic ischemia on splanchnic hemodynamics and on BSP removal by liver. Proc. Soc. exp. Biol. (N. Y.) 1954, 87, 307.
30. Bradley, S. E., F. J. Ingelfinger, and G. P. Bradley. Determinants of hepatic haemodynamics in Visceral Circulation, Ciba Foundation. Iondon, J. \& A. Churchill, 1952, p. 225.

31. Bradley, S. E. Liver function as studied by hepatic vein catheterization in Transactions of the Fifth Conference on Liver Injury. New York, Josiah Macy, Jr., Foundation, 1946, p. 38.

32. Brauer, R. W. Liver circulation and function. Physiol. Rev. 1963, 43, 115.

33. Bradley, S. E., F. J. Ingelfinger, G. P. Bradley, and J. J. Curry. The estimation of hepatic blood flow in man. J. clin. Invest. 1945, 24, 890.

34. Cassels, D. E., and M. Morse. Blood volume and exercise. J. Pediat. 1942, 20, 352.

35. Cullumbine, H., and A. C. E. Koch. The changes in plasma and tissue fluid volume following exercise. Quart. J. exp. Physiol. 1949, 35, 39.

36. Knisely, M. H., F. Harding, and H. Debacker. Hepatic sphincters, brief summary of present-day knowledge. Science 1957, 125, 1023.

37. Caesar, J., K. M. Barber, E. Baraona, and S. Sherlock. The estimation of portal-systemic collateral flow in man using intrasplenic injection of radioactive indicator. Clin. Sci. 1962, 23, 77.

38. Taylor, H. L., Y. Wang, L. B. Rowell, and G. Blomqvist. The standardization and interpretation of submaximal and maximal tests of working capacity. Pediatrics (suppl.) 1963, 32, 703.

39. Wang, Y., J. T. Shepherd, R. J. Marshall, L. Rowell, and H. L. Taylor. Cardiac response to exercise in unconditioned young men and in athletes (abstract). Circulation 1961, 24, 1064.

40. Wang, Y., L. B. Rowell, G. Blomqvist, and H. L. Taylor. The effects of a conditioning program on the cardiovascular function in exercise of sedentary college males. In preparation.

41. Wyndham, C. H., N. B. Strydom, C. G. Williams, and $M$. von Rahden. A physiological basis for the 'optimum' level of energy expenditure. Nature (Lond.) 1962, 195, 1210.

42. Rowell, L. B., H. L. Taylor, and Y. Wang. Limitations to the prediction of maximal oxygen intake. J. appl. Physiol. 1964, in press. 